\title{
Role of transvaginal sonography and hysteroscopy in abnormal uterine bleeding: does the diagnostic yield increase by combining transvaginal sonography, hysteroscopy and biopsy?
}

\author{
Nivedita Krishnamoorthy, Fatima Shanthini N*
}

\begin{abstract}
Department of Obstetrics \& Gynecology, Sree Manakula Vinayagar Medical College and Hospital,
\end{abstract} Kalitheerthalkuppam-605107, Puducherry, India

Received: 27 August 2014

Accepted: 19 September 2014

\section{*Correspondence:}

Dr. Fatima Shanthini N,

E-mail: nfshanthini@yahoo.co.in

Copyright: () the author(s), publisher and licensee Medip Academy. This is an open-access article distributed under the terms of the Creative Commons Attribution Non-Commercial License, which permits unrestricted non-commercial use, distribution, and reproduction in any medium, provided the original work is properly cited.

\begin{abstract}
Background: Abnormal uterine bleeding is the most common complaint of perimenopausal and postmenopausal women. The aim of this study was 1) To evaluate the causes of abnormal uterine bleeding using transvaginal sonography, hysteroscopy and endometrial curettage to achieve the greatest diagnostic accuracy. 2) To determine the sensitivity and specificity of TVS and hysteroscopy in the detection of various uterine pathologies.

Methods: This was a descriptive cross sectional study between January 2013 to June2014 in Sri Manakula Vinayagar medical college and hospital. After obtaining ethics committee approval, 100 consecutive patients with abnormal uterine bleeding between the age group of 35 and 55 years, who consented to participate in the study, were subjected to transvaginal sonography followed by diagnostic hysteroscopy combined with a directed biopsy. TVS and hysteroscopy was performed by two different investigators. The endometrial curettings and any intracavitary lesion were subjected to histopathological examination. Results tabulated and analysed using MS EXCEL and cross tabulation using Epi-info. Sensitivity, specificity, PPV, NPV for each pathology by TVS and hysteroscopy with HPE as the gold standard was calculated. Also the pathology causing abnormal uterine bleeding was computed by taking into account the endometrial characteristics and the associated lesions diagnosed by TVS, hysteroscopy and histopathological examination report.

Results: 61 patients had only single lesions in the form of normal endometrium, atrophic endometrium, endometrial hyperplasia, endometrial polyp, malignancy and IU synechiae whereas 39 patients had lesions like intramural fibroids, adenomyosis, submucus myoma and polyps associated with different types of endometrium. The diagnostic accuracy of TVS and hysteroscopy were comparable for normal endometrium whereas hysteroscopy was found to be more accurate for endometrial polyps, endometrial hyperplasia and atrophic endometrium.

Conclusions: The combination of transvaginal sonography, hysteroscopy and directed biopsy was found to increase the diagnostic yield in patients with abnormal uterine bleeding. As the diagnostic accuracy increased by combining the three modalities, an effective and appropriate management can be planned.
\end{abstract}

Keywords: Abnormal uterine bleeding, Transvaginal sonography, Hysteroscopy, Biopsy

\section{INTRODUCTION}

Abnormal uterine bleeding is the most common gynecological complaint encountered in both perimenopausal and postmenopausal women.
Transvaginal sonography is useful to detect causes of abnormal uterine bleeding like fibroids, adenomyosis, endometrial polyp and adnexal pathology and also to determine endometrial thickness and morphology as well as regularity of the endo myometrial border. ${ }^{1}$ TVS cannot 
definitely exclude sessile and pedunculated lesions of the endometrium and malignancy and also has a high false negative rate in diagnosing focal intrauterine pathology. ${ }^{2,3}$ TVS is used as the primary modality in investigating the cause of abnormal uterine bleeding.

Hysteroscopy is an invasive procedure which is less often performed than TVS due to its invasiveness and need for trained personnel but it remains highly sensitive and specific for intra cavitary uterine lesions like endometrial polyps and submucus myomas. It identifies discrete lesions but does not give histological diagnosis. ${ }^{4}$

Dilatation and curettage is considered the gold standard for the diagnosis of AUB but blind curettage covers less than half of the endometrial cavity in $60 \%$ of the procedures. $^{5}$ A combination of hysteroscopy and directed biopsy is highly sensitive in cases of malignant and premalignant lesions. ${ }^{6}$

\section{The aim of this study was}

1. To evaluate the causes of abnormal uterine bleeding using transvaginal sonography, hysteroscopy and endometrial curettage to achieve the greatest diagnostic accuracy.

2. To determine the sensitivity and specificity of TVS and hysteroscopy in the detection of various uterine pathologies.

\section{METHODS}

This is a descriptive cross sectional study carried out in Sree Manakula Vinayagar medical college \& hospital between January 2013 and June 2014. Institutional ethics committee approval was obtained. 100 consecutive patients with complaints of abnormal uterine bleeding between the age group of 35 and 55 years who consented to participate in the study were selected, the exclusion criteria being active pelvic infection, obvious vaginal, vulval or cervical causes of bleeding and patients on hormones.

All the patients were subjected to general and pelvic examination followed by basic laboratory workup.
Conventional 2D transvaginal sonography was performed using Acuson X300 scanner with 4-7 MHZ endovaginal probe in all these patients by one of the investigators and following information was recorded in a proforma. The endometrium was categorized as proliferative, secretory, atrophic or hyperplastic and presence of intramural or submucus fibroid, endometrial polyps, adenomyosis, any suspected malignancy, endometrial thickness and adnexal mass were noted.

These patients were admitted and diagnostic hysteroscopy was performed under short GA using a Karl Storz hysteroscope with $30^{\circ}$ fibreoptic lens with normal saline as the distension media. Endometrium was again categorized as proliferative, secretory, atrophic or hyperplastic and also presence of any intra cavitary lesions were noted. TVS and hysteroscopy were performed by different gynecologists, the person performing hysteroscopy being blinded for TVS findings. At the same time hysteroscopy guided endometrial curettage was performed and curettings and polyps obtained were sent for histopathological examination.

The results were tabulated and analysed using MS excel and cross tabulation using Epi-info software and sensitivity and specificity, positive predictive value and negative predictive value for each pathology was calculated using histopathological examination report as the gold standard. The cause of AUB was computed taking into account the findings obtained by transvaginal sonography, hysteroscopy and biopsy report.

\section{RESULTS}

The mean age of the patients with AUB was 42.9 years. 97 patients were multiparous and 3 were nulliparous. 71 patients presented with complaints of menorrhagia, 19 with postmenopausal bleeding, 8 with irregular bleeding and 2 with blood stained discharge.

Taking endometrial lesion as the primary pathology detected by each modality the additional pathology detected by TVS and hysteroscopy in presented in Table 1.

Table 1: Pathology detected by each modality and the additional pathology detected by TVS and hysteroscopy.

\begin{tabular}{|c|c|c|c|c|c|c|c|c|c|c|c|}
\hline \multirow[b]{2}{*}{$\begin{array}{l}\text { EM pathology } \\
\text { detected by } \\
\text { each modality }\end{array}$} & \multicolumn{5}{|c|}{ TVS findings } & \multicolumn{6}{|c|}{ Hysteroscopy findings } \\
\hline & $\begin{array}{l}\text { No. } \\
\text { associated } \\
\text { lesions }\end{array}$ & $\begin{array}{l}\text { IM } \\
\text { fibroid }\end{array}$ & $\begin{array}{l}\text { Adeno- } \\
\text { myosis }\end{array}$ & $\begin{array}{l}\text { EM } \\
\text { polyp }\end{array}$ & $\begin{array}{l}\text { SM } \\
\text { fibroid }\end{array}$ & $\begin{array}{l}\text { No. } \\
\text { associated } \\
\text { lesions }\end{array}$ & $\begin{array}{l}\text { IM } \\
\text { fibroid }\end{array}$ & $\begin{array}{l}\text { Adeno- } \\
\text { myosis }\end{array}$ & $\begin{array}{l}\text { EM } \\
\text { polyp }\end{array}$ & $\begin{array}{l}\text { SM } \\
\text { fibroid }\end{array}$ & $\begin{array}{l}\text { IU } \\
\text { synechia }\end{array}$ \\
\hline Atrophic EM & 6 & 0 & 1 & 0 & 0 & 11 & - & - & 4 & 1 & - \\
\hline End. hyperplasia & 17 & 8 & 3 & 3 & 3 & 24 & - & - & 10 & 2 & - \\
\hline Malignancy & 1 & - & - & - & - & 1 & - & - & - & - & - \\
\hline IU synechia & - & - & - & - & - & - & - & - & - & - & 1 \\
\hline
\end{tabular}


TVS detected 23 cases of intramural fibroid and 8 cases of adenomyosis along with different types of endometrium. 6 patients were diagnosed to have endometrial polyp along with different types of endometrium. In 3 patients endometrial polyp was the primary lesion as endometrial characteristics could not be defined. 3 patients with endometrial hyperplasia were suspected to have a sub mucus fibroid along with endometrial lesion of which 2 were confirmed by hysteroscopy subsequently. The intramural fibroids varied in size between $2 \mathrm{~cm}$ to $6 \mathrm{~cm}$ and the diagnosis of adenomyosis were made by the typical USG findings like anteroposterior asymmetry of the myometrium, poor endomyometrial differentiation, presence of myometrial cysts etc.

Hysteroscopy diagnosed almost 25 cases of endometrial polyp ranging between $2 \mathrm{~mm}$ to $1 \mathrm{~cm}$ and 4 cases of submucus fibroid along with the primary endometrial findings and 8 cases of endometrial polyp individually. It also detected 1 case of IU synechia but we did not diagnose any cases of adenomyosis even though typical adenomyotic features by hysteroscopy are defined.
1 patient was diagnosed to have a malignant growth by both TVS and hysteroscopy. The histopathological report of the endometrial curettings obtained on D \& C guided by hysteroscopy is depicted in Table 2 .

Table 2: Pathological confirmation not available for intramural or submucus fibroid and adenomyosis.

\begin{tabular}{|l|l|}
\hline HIPE report n-100 & No. \\
\hline Normal endometrium & 48 \\
\hline Endometrial hyperplasia & 33 \\
\hline Atrophic EM & 2 \\
\hline Malignancy & 1 \\
\hline EM polyp & 11 \\
\hline Normal EM + polyp & 3 \\
\hline Endometrial hyperplasia + polyp & 2 \\
\hline
\end{tabular}

Taking into consideration the findings obtained by all the three modalities (TVS, hysteroscopy and endometrial histopathology) the final diagnosis was made which is depicted in Table 3.

Table 3: Diagnosis combining endometrial characteristics and associated lesions.

\begin{tabular}{|llllll|}
\hline Endometrial pathology & $\begin{array}{l}\text { No. } \\
\text { associated } \\
\text { lesions }\end{array}$ & $\begin{array}{l}\text { IM } \\
\text { fibroid }\end{array}$ & Adenomyosis & $\begin{array}{l}\text { EM } \\
\text { polyp }\end{array}$ & $\begin{array}{l}\text { SM } \\
\text { fibroid }\end{array}$ \\
\hline Normal endometrium & 28 & 12 & 5 & 3 & 1 \\
\hline Atrophic endometrium & 2 & 0 & - & 1 & 1 \\
\hline Endometrial hyperplasia & 21 & 9 & 2 & 2 & 2 \\
\hline Malignancy & 1 & - & - & - & - \\
\hline EM polyp & 9 & - & - & - & - \\
\hline IU synechiae & 1 & - & - & - & - \\
\hline
\end{tabular}

Single lesions with histological confirmation (endometrial pathology only) was as follows: 28 patients had normal endometrium, 2 had atrophic endometrium, 21 patients had endometrial hyperplasia and 9 patients had endometrial polyps and 1 patient was diagnosed to have malignancy which was an adenosquamous carcinoma (Total - 61).

Other patients (No-39) had an additional pathology along with the endometrial lesion. 12 IM fibroids and 5 adenomyosis were found to be associated with normal endometrium whereas 9 IM fibroids and 2 cases of adenomyosis were found to be associated with endometrial hyperplasia. 5 patients were diagnosed to have EM polyp along with the endometrial lesions whereas in 9 patients with EM polyps endometrial lesion was not defined. 4 patients were diagnosed to have sub mucus myoma and 1 patient had IU synechiae.
Histological confirmation is not available for IM fibroids, adenomyosis, sub mucus myoma and IU synechiae as many of these patients were treated by conservative management.

On subsequent follow up of these patients 2 cases of Intramural fibroid, 1 case of submucus fibroid and 5 cases of adenomyosis were confirmed after hysterectomy. The above results indicate that combining all the three modalities will increase the diagnostic accuracy in cases of AUB.

The sensitivity, specificity, positive predictive value and negative predictive value of TVS hysteroscopy for different lesions with histopathological examination as the gold standard is shown in Table 4. 
Table 4: The sensitivity, specificity, positive predictive value and negative predictive value of TVS hysteroscopy for different lesions with histopathological examination as the gold standard.

\begin{tabular}{|c|c|c|c|c|c|c|c|c|}
\hline \multirow{2}{*}{$\begin{array}{l}\text { Histopathological } \\
\text { examination report }\end{array}$} & \multicolumn{4}{|l|}{ TVS } & \multicolumn{4}{|c|}{ Hysteroscopy } \\
\hline & Sensitivity\% & Specificity\% & PPV\% & NPV\% & Sensitivity\% & Specificity\% & PPV\% & NPV\% \\
\hline Proliferative endometrium & 30.43 & 90.91 & 50 & 81.4 & 27.27 & 88.61 & 40 & 81.4 \\
\hline Secretory endometrium & 46.67 & 71.83 & 41.18 & 76.12 & 40.74 & 80.28 & 44 & 78.08 \\
\hline Endometrial hyperplasia & 45.71 & 76.56 & 51.61 & 72.06 & 60 & 78.12 & 60 & 78.12 \\
\hline Atrophic endometrium & 50 & 94.95 & 16.67 & 98.95 & 100 & 85.71 & 12.5 & 100 \\
\hline Endometrial polyp & 56.25 & 91.67 & 56.25 & 91.678 & 93.75 & 78.57 & 45.45 & 98.5 \\
\hline Malignancy & 100 & 100 & 100 & 100 & 100 & 100 & 100 & 100 \\
\hline
\end{tabular}

The sensitivity and specificity of TVS and hysteroscopy for proliferative and secretory endometrium were comparable whereas the sensitivity and specificity of hysteroscopy for endometrial hyperplasia was better than TVS (60\% \& $78.12 \%$ vs. $45.71 \%$ \& 76.56\%) Again hysteroscopy was found to be more sensitive and specific in predicting atrophic endometrium than TVS $(100 \%$ \& $85.71 \%$ vs. $50 \%$ \& $94.95 \%$ ) and also accurate in the diagnosis of endometrial polyp $(93.75 \% \& 75.5 \%$ vs. $56.25 \% 91.67 \%$ ). Both TVS and hysteroscopy diagnosed a case of malignancy which was confirmed by histopathological examination.

\section{DISCUSSION}

The successful management of AUB depends upon accurate diagnosis which in turn depends upon choosing the investigation with highest sensitivity and specificity for any pathology causing AUB.

TVS was found to have a sensitivity and specificity of $69.3 \%$ and $82.7 \%$ in differentiating normal from pathological endometrium in a study by Conoscenti et al. ${ }^{7}$ The study also showed that TVS had a poor diagnostic accuracy in detecting endometrial benign lesions, polyps and malignancy. In our study we found that sensitivity and specificity for normal endometrium to be low and for other benign endometrial lesions the sensitivity and specificity were as follows: $45.71 \%$ \& $75.56 \%$ for endometrial hyperplasia $50 \%$ \& $94.95 \%$ for atrophic endometrium and $56.25 \% \& 91.67 \%$ for endometrial polyp. 1 patient suspected to have a malignant growth was confirmed by histopathology.

TVS showed a sensitivity and specificity of $77.3 \& 76 \%$ for intramural fibroids. ${ }^{8}$ For adenomyosis the sensitivity and specificity of TVS was $84.55 \& 43.40 \% .^{9}$ In our study 23 cases of IM fibroids varying in size between 2 $\mathrm{cm}$ and $6 \mathrm{~cm}$ were diagnosed by TVS and 8 patients were diagnosed to have adenomyosis but histological confirmation was not possible due to non-availability of representative sample. TVS also identified submucus myoma but is not very specific as it can be mistaken for endometrial polyp. ${ }^{10}$ In our study too TVS detected submucus myoma in 3 cases of which 2 were confirmed subsequently by hysteroscopy
In a study by Sheetal et al. the sensitivity and specificity of hysteroscopy for proliferative endometrium was $78.5 \%$ and $86.2 \%$ and for secretory endometrium $54.54 \%$ and $93.58 \% .{ }^{11}$ Our study showed a sensitivity and specificity of $27.27 \%$ and $88.61 \%$ for proliferative endometrium and $40.74 \%$ and $80.28 \%$ for secretory endometrium. For endometrial hyperplasia the sensitivity and specificity was found to be $75 \%$ and $92.5 \%$ in the above study. ${ }^{11} \mathrm{~A}$ study on validity of hysteroscopy showed a sensitivity and specificity of $63 \%$ and $92 \%$ for endometrial hyperplasia and $89 \%$ and $96 \%$ for atrophic endometrium. $^{12}$ The sensitivity and specificity for endometrial hyperplasia and atrophic endometrium was found to $60 \%$ and $78.12 \%$ and $100 \%$ and $85.71 \%$ respectively in our study which was comparable to the previous studies. The highest sensitivity and specificity by hysteroscopy was found for endometrial polyps and malignancy in our study which was similar to other studies. Sheetal et al. reported a sensitivity and specificity of $100 \%$ and $95.78 \%$ for endometrial polyps and $100 \%$ and $98.97 \%$ for malignancy. ${ }^{11}$ Tajossadat et al. reported a sensitivity and specificity of $93 \%$ and $100 \%$ for EM polyps and $100 \%$ and $96.4 \%$ for submucus myoma. ${ }^{13}$ In our study 4 cases of sub mucus myoma and 1 case of IU synechiae were diagnosed by hysteroscopy. As discussed previously in $60 \%$ of patients undergoing blind curettage only half the cavity was curetted whereas in another study it was found blind curettage covers as much as $60 \%$ of the cavity but may miss polyps. ${ }^{5,14}$

The above findings indicate that each modality has its own limitations. The accuracy of TVS in the diagnosis of IM fibroids and adenomyosis is good but it cannot differentiate between EM polyps, hyperplasia and early cancers. Hysteroscopy is superior to TVS in the diagnosis of intracavitary lesions like polyps and submucus myoma. Mojgan Barati et al. recommends hysteroscopy for patients with AUB as the second step even if TVS is normal. ${ }^{16}$ Sensitivity to endometria hyperplasia by hysteroscopy may be high but it cannot replace histological diagnosis to differentiate between benign and malignant pathology. Hysteroscopy also guides us to perform a directed biopsy from the suspected lesions. As described in an earlier study when both TVS and hysteroscopy are combined the diagnostic accuracy increased in cases of AUB. ${ }^{17}$ 
Taking the endometrial characteristics also into consideration along with pathology like intramural fibroids and adenomyosis, an effective strategy for management can be planned. Diagnosis of a normal endometrium or normal endometrium with small fibroid or adenomyosis in the perimenopausal age group can be effectively treated with medical management like antifibrinolytic agents whereas fibroid or adenomyosis associated with benign endometrial hyperplasia would warrant treatment with progesterones. A submucus fibroid or polyp overlooked by transvaginal sonography associated even with a normal endometrium could be a cause of persistent irregular bleeding when hysteroscopy is not performed. An atrophic endometrium is amenable to treatment with hormone replacement whereas atrophic endometrium associated with submucus myoma missed by TVS may need surgical management.

To conclude, a combination of all the three modalities (Transvaginal sonography/hysteroscopy and endometrial biopsy) was found to increase the diagnostic accuracy in patients with abnormal uterine bleeding and will effectively guide us in planning the appropriate management for these patients.

\section{ACKNOWLEDGEMENTS}

We sincerely thank prof. Dr. A. Bupathy HOD, dept. of obstetrics \& gynecology, Indira Gandhi medical college and hospital, Puducherry who was our former HOD for his guidance throughout this study.

\section{Funding: No funding sources}

Conflict of interest: None declared

Ethical approval: The study was approved by the institutional ethics committee

\section{REFERENCES}

1. Karlsson B, Granberg S, Wikland M, Ylöstalo P, Torvid K, Marsal K, et al. Transvaginal ultrasonography of the endometrium in women with postmenopausal bleeding: a Nordic multicenter study. Am J Obstet Gynecol. 1995;172:1488-94.

2. Mortakis AK, Mavrelos K. Transvaginal ultrasonography and hysteroscopy in the diagnosis of endometrial abnormalities. J Am Assoc Gynecol Laparosc. 1997;4:449-52.

3. Bombiesi L, Hogston P. Endometrial carcinoma with an endometrial thickness of $3.2 \mathrm{~mm}$ on vaginal ultrasonography. J Obstet Gynecol. 1995;15:421.

4. Hunter DC, Mc Clure N. Abnormal uterine bleeding: an evaluation of endometrial biopsy, vaginal ultrasound and outpatient hysteroscopy. Ulster Med J. 2001;70:25-30.

5. Lawrence P, O Connell, Fries MH, Zeringue E, Brehm W. A comparison of endometrial biopsy and transvaginal sonohysterography versus fractional curettage with hysteroscopy. J Obstet Gynecol. 1998;178:956-61.
6. Mencaglia L, Valle RF, Perino A, Gilardi G. Endometrial carcinoma and its precursor. Early detection and treatment. Int $\mathbf{J}$ Gynecol Obstet. 1990;31:107-16.

7. Conoscenti G, Meir YJ, Fischer-Tamaro, Maieron A, Natale R, D'ottavio, et al. Endometrial assessment by transvaginal sonography and histological findings after D \& C in women with postmenopausal bleeding. Ultrasound Obstet Gynecol. 1995;6:10815.

8. Reddi Rani P, Lakshmikantha G. Transvaginal sonography and saline infusion sonohysterography in the evaluation of abnormal uterine bleeding. J Obstet Gynecol India. 2010;60(6):511-5.

9. Hanafi M. Ultrasound diagnosis of adenomyosis, leiomyoma or combined with histopathological correlation. J Hum Reprod Sci. 2013;6(3):189-93.

10. Tahir MM, Bigrigg MA, Browning JJ, Brookes ST, Smith A. A randomized controlled trial comparing transvaginal ultrasound, outpatient hysteroscopy and endometrial biopsy with inpatient hysteroscopy and curettage. Br J Obstet Gynecol. 1999;106,1259-64.

11. Patil G, Bhute SB, Inamdar SA, Acharya S, Shrivatsava S. Role of diagnostic hysteroscopy in abnormal uterine bleeding and its histopathologic correlation. J Gynecol Endosc Surg. 2009;1:98-104.

12. Shazia F, Ghazala M. Validity of hysteroscopy and histopathology in patients with menstrual irregularity. J Ayub Med Coll Abbottabad. 2010;22(1):129-32

13. Tajossadat A, Fereshteh M. Diagnostic value of hysteroscopy is abnormal uterine bleeding compared to pathology reports. Iranian $\mathrm{J}$ Reprod Med. 2007;5(2):61-4.

14. Schei B, Bang TF. Halgunset J, Haugen OA, Tlaarsatd I, Onsrud M. Micro curettage sampling of the endometrium for histopathological examination: simpler but not safe? Comparison of endometrial histopathology is samples obtained by a disposable mechanical curette and by traditional curettage. Acta Obset Gynecol Scand. 1994;73:497-501.

15. Feng L, Xia E, Duan H. Diagnosis of uterine disease by combined hysteroscopy and ultrasonography. Chinese J Obstet Gynecol. 1996;31:334-7.

16. Mojgan B, Sara M, Farideh M, Shabnam S. Off ice hysteroscopy in patients with abnormal uterine bleeding and normal transvaginal sonography. Int $\mathbf{J}$ Fertil Steril. 2008;4:175-8.

17. Al-Kubaisi RI. The relationship between hysteroscopy, endometrial biopsy and the results of transvaginal sonography in assessing endometrial polyps. Sultan Qaboos Univ Med J. 2007;7:51-4.

DOI: $10.5455 / 2320-1770$. ijrcog20141209

Cite this article as: Krishnamoorthy N, Fatima Shanthini N. Role of transvaginal sonography and hysteroscopy in abnormal uterine bleeding: does the diagnostic yield increase by combining transvaginal sonography, hysteroscopy and biopsy? Int J Reprod Contracept Obstet Gynecol 2014;3:919-23. 